\title{
CONGENITAL RIGHT DIAPHRAGMATIC HERNIA ASSOCIATED WITH FALLOT'S TETRALOGY \\ BY
}

\author{
L. I. HATHERLEY \\ London
}

Congenital diaphragmatic hernia is an uncommon condition, especially when right sided and associated with the tetralogy of Fallot. Either of these conditions may cause cyanosis of the newborn and present difficulties in exact diagnosis. It is well known that the early diagnosis of the tetralogy is often impossible ; a cardiac lesion may be suspected, but its exact nature remains obscure.

\section{CAse History}

The patient was the first born child to the Italian wife of a white American soldier. The mother, aged 18 years, had enjoyed normal health during pregnancy and had not been in known contact with rubella or influenza. In neither side of the family had a congenital defect been known to occur in previous generations.

At birth (31.5.49) the child was noticed to be cyanosed and feeble with rapid, shallow respirations. The right side of the chest failed to move with the left on respiration and the apex beat was shifted to the left. Normal air entry was present on the left and absent on the right side. The heart sounds were clear and of good quality. No murmurs were heard. The abdomen had a hollow appearance, quite unlike the rotund fullness generally seen in the newborn, and on palpation it felt empty. Peristalsis was not heard in the chest or abdomen. Otherwise the child appeared normal and well nourished.

A radiograph (Fig. 1) showed that the entire right hemithorax was filled with bowel, both large and small, extending up to the apex of the thoracic cavity. No aerated lung tissue was visible and the mediastinum had a considerable shift to the left. What visible lung tissue there was on the left side appeared normal. The heart shadow was thought to be within normal limits. The abdomen was devoid of shadows other than that of a dilated stomach and part of the large intestine. A massive right diaphragmatic hernia through a postero-lateral hiatus was diagnosed.

It was decided to operate as soon as the condition of the child had been improved as far as possible with oxygen and warmth. The operation was started nine hours after birth.

Operation.-The anaesthetic chosen was a combination of ether inhalation and novocaine infiltration, a high oxygen concentration being maintained throughout. The stomach was aspirated continuously.

A right Kocher incision was made to approach the diaphragm from below. The peritoneal cavity was empty apart from stomach and pelvic colon stretched taut between rectum and diaphragm. Respiration continued unaided after the abdomen was opened indicating the tightness with which bowel was impacted through the gap in the diaphagm.

After introducing air above the obstruction, the bowel was reduced and found to be strangulated. It was dark purple in colour, dull, and the loops distended (despite 


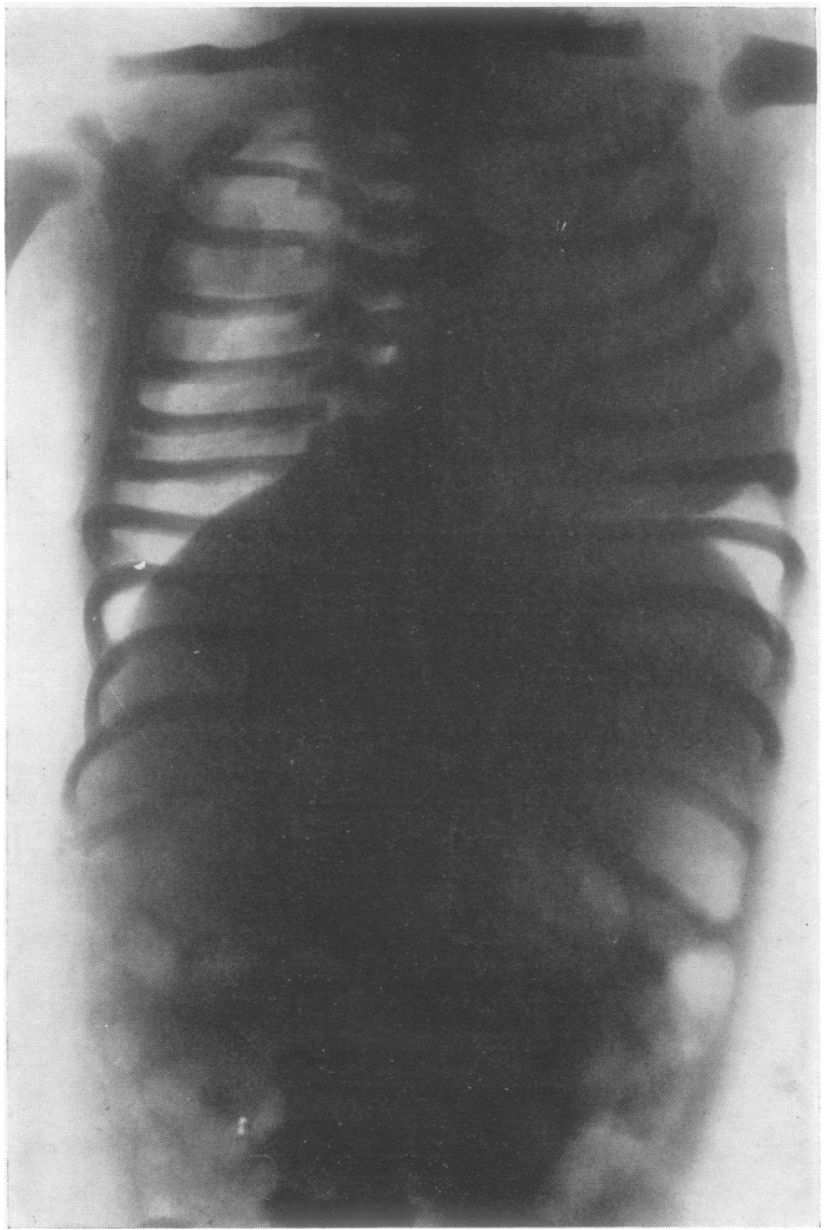

FiG. 1.-Radiograph taken after birth (May 31, 1949). the presumed absence of bacteria within the lumen), and ecchymoses were present in the mesentery. About $50-60 \mathrm{ml}$. of blood clot was also present, some of which was still fluid and some partly organized and resembling a carneous mole. The right lobe of the liver was twisted upwards so that the inferior border passed medial to the bowel into the thorax. The constriction had produced a pyramidal zone $(3 \mathrm{~cm}$. square) closely resembling infarction.

The defect was oval in shape directed forwards and laterally. It approached to within a centimetre of the oesophagus and extended forwards into the anterior part of the diaphragm. Posteriorly and laterally rather less than a centimetre of diaphragm was present.

The diaphragmatic tissue was sufficiently elastic to allow the gap to be sutured directly along its long axis using a continuous silk suture reinforced with interrupted

stitches. The lung was inflated as far as possible before finally closing the opening. As the suture was strong enough to withstand positive pressure, it was decided not to crush the phrenic nerve later.

The condition of the bowel had meanwhile improved and was considered viable. The closing of the abdomen, previously unexpanded with bowel, was by far the most difficult and protracted part of the operation. The liver being well to the left offered none of its usual assistance in keeping the wound free from bowel. The incision was ultimately closed in layers.

At the end of the operation, meconium was passed and frequent bowel movements occurred during the next few days. The stools were normal. A radiograph (Fig. 2) taken immediately after the operation showed that the intestines were intra-abdominal and that a somewhat straightened diaphragm separated the pleural and abdominal cavities. The right lung was partly expanded, but the diaphragm was still shifted to the left. 
About 12 hours postoperatively the infant suddenly collapsed, necessitating prolonged artificial respiration before breathing re-started and the pulse became perceptible. The stomach was kept empty for the first 36 hours, fluids being supplied subcutaneously, together with ascorbic acid and prophylactic penicillin.

Feeds were well taken. Expressed breast milk, later changed to reconstituted evaporated milk with an added vitamin complex, was given threehourly. After an initial slight loss of weight from $7 \mathrm{lb}$. at birth to $6 \mathrm{lb} .10 \mathrm{oz}$. on June 11, the child gained steadily. By June 22 the birth weight was regained and from then until July 19 (eight weeks after birth) when the child weighed 8 lb. 9 oz., gained an ounce a day.

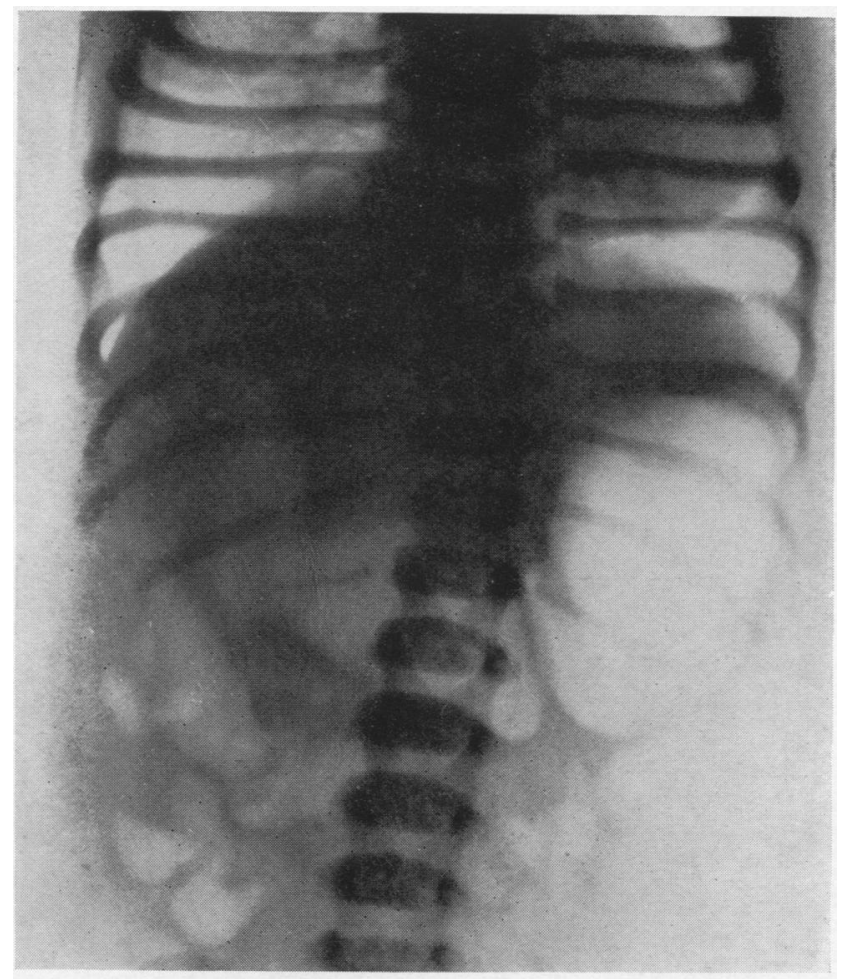

FIG. 2.--Radiograph taken immediately after operation (June 1, 1949).

Thereafter there was a gradual terminal loss of weight.

A blood count on June 4 showed a moderate anaemia:

R.B.C. $2,810,000$ per c.mm. ; Hb 11.5 g. ;

W.B.C. 14,750 per c.mm.

Then $40 \mathrm{ml}$. of blood was transfused and the blood count on June 6 was:

R.B.C. 4,900,000 per c.mm. ; Hb 16.0 g. ; W.B.C. 19,150 per c.mm.

\section{Subsequent total and differential counts were normal.}

The cyanosis continued to a varying extent following operation despite satisfactory lung expansion. When seen on a fluoroscopic screen (June 15) the right hemidiaphragm had a taut appearance with limited respiratory excursions $(50 \%)$ which were jerky compared with the smooth rhythmical movements of the left side. The lung was now fully expanded.

The heart became progressively enlarged, periodic failure with intense cyanosis occurred, and the wound, after appearing to heal soundly, broke down. Only when an increased blood supply to the part was induced with infra-red radiation did the wound heal. An electrocardiogram (June 21 ) showed clearly a right ventricular preponderance and normal rhythm. On July 8 a sudden deterioration occurred. The cyanosis deepened, crops of petechiae and purpuric spots appeared on the face and body, and a soft systolic murmur was audible over the whole precordium. The air entry over both lungs remained 


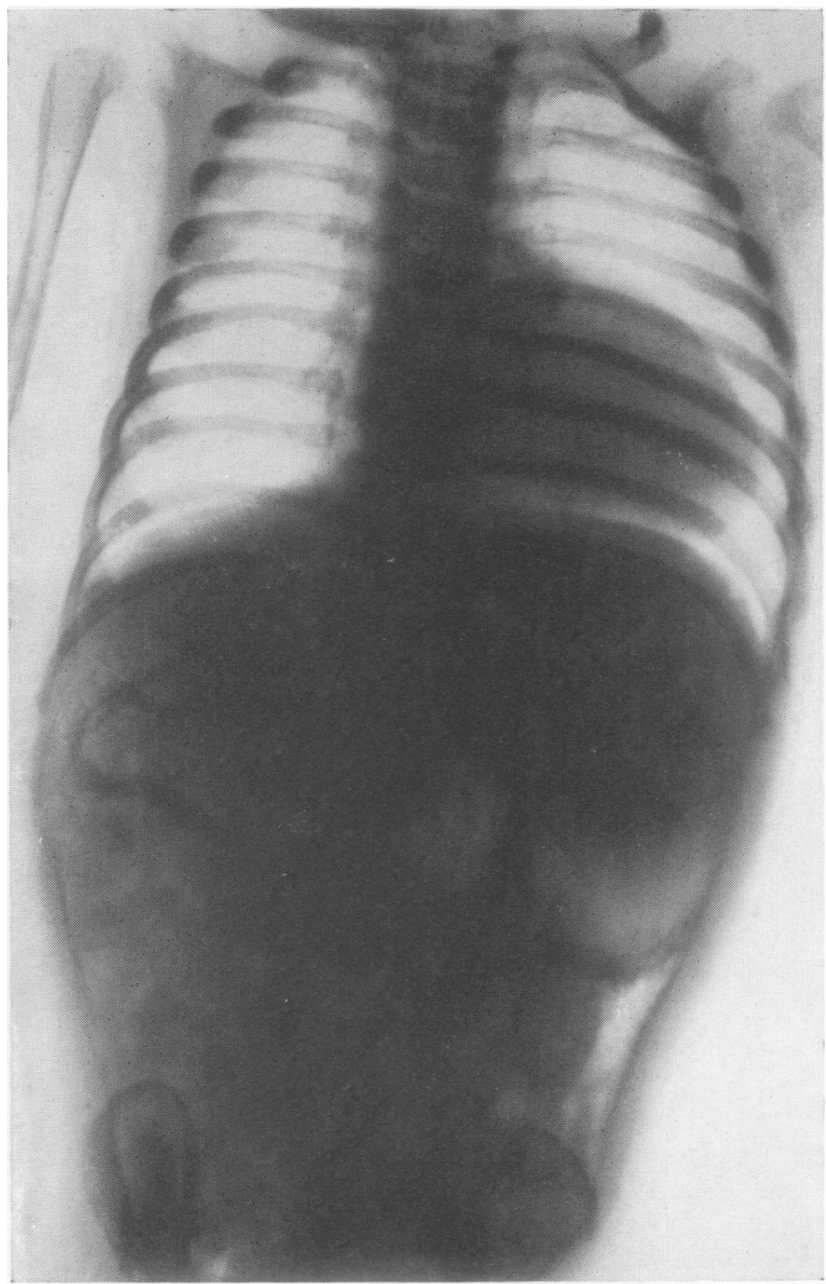
1949).
Fig. 3.-Radiograph taken a few hours before death (July 29,

good and adventitious sounds were absent. The child appeared comatose and the temperature rose to $101-102^{\circ} \mathrm{F}$. This syndrome suggested endocarditis despite its rarity at this age. A positive blood culture was not obtained, but combined chemotherapy was instituted empirically. Rapid improvement ensued and the child regained his vigour. The temperature subsided, the haemorrhages faded, the murmur disappeared, and the cyanosis lessened, but a relapse on July 22 failed to respond to further treatment and the child died on July 30, 92 days after operation. A radiograph (Fig. 3) taken on July 29 showed a heart shadow of coeur en sabot.

\section{Post-mortem Findings}

In the abdomen, apart from multiple adhesions and the position of the liver, there was little of note. The liver (150 g.) was normal and no trace of the lesion seen at operation was present.

The heart was markedly enlarged (transverse diameter $6 \mathrm{~cm}$.) from hypertrophy and dilatation of the right ventricle, the myocardium of which was thicker than that of the left ventricle. The aorta arose from the right ventricle straddling a septal defect measuring $1.0 \mathrm{~cm}$. $\times 0.8 \mathrm{~cm}$. and was relatively very large, measuring $3.4 \mathrm{~cm}$. in circumference (diameter $1.1 \mathrm{~cm}$.). The pulmonary trunk, a thin atretic vessel of circumference $0.4 \mathrm{~cm}$. (diameter $0.1 \mathrm{~cm}$.), included the pulmonary orifice, continued up to the lungs without expanding distal to a patent ductus arteriosus. The ductus, which was equal in size to the pulmonary artery, connected these vessels $2.0 \mathrm{~cm}$. from the heart. The mitral, tricuspid, and aortic valves were normal, but the pulmonary valve was apparently absent. There was no evidence of mural or valvular endocarditis.

The lungs were pale pink and free from congestion or atelectasis. The upper surface of the right half of the diaphragm was symmetrical with the left, and the flattened, taut appearance seen radiographically was no longer evident. The suture line was not discernible. 


\section{Discussion}

Many authors, mainly American, have recommended that the phrenic nerve be paralysed preparatory to repair of the diaphragmatic defect. The diaphragm is either repaired immediately or repair is delayed for several days or even months. The purpose of the paralysis is to "facilitate the closure of the hernial opening and to prevent excessive strain on the suture line during healing of the diaphragmatic wound" (Ladd and Gross, 1940).

Although the defect in this case was large, the very considerable elasticity of the diaphragm enabled the gap to be closed without the preliminary step of phrenic crush. Early repair prevents adhesions forming within the thorax and ensures full lung expansion. Before closing the abdomen the suture line may be tested by applying positive pressure greater than the tension to which it would reasonably be subjected during active diaphragmatic movements. By merely crushing the phrenic nerve, some relaxation of the diaphragmatic constriction occurs, but this may be insufficient to prevent strangulation later. In this case when the operation was begun nine hours after birth, strangulation had already occurred. As there were no pre-operative signs of strangulation, it would have been missed but for laparotomy.

As the most difficult part of the operation is closing the abdomen, it is expedient, when all factors have been considered, to operate as soon as possible after birth while the bowel remains undilated. This considerable advantage is lost by delaying laparotomy with or without a phrenic nerve section.

\section{SUMMARY}

The case history and necropsy findings of a case of congenital right diaphragmatic hernia associated with a congenital heart lesion is recorded.

The complication of haemothorax due to strangulation of the hernia is described.

Post-operative recovery of full respiratory function, and the insidious manner in which the cardiac lesion became manifest is described.

Comparison is made between the operative technique employed and that described in previous cases.

I am indebted to Lieut.-Col. H. K. G. Nash, R.A.M.C., A.D.M.S., B.E.T.F.O.R., and to Lieut.-Col. Martin O. Stauch, M.C., A.U.S., Officer Commanding American 7th Station Hospital, T.R.U.S.T., for permission to publish this case. I should also like to acknowledge the valuable assistance freely given me by all ranks at the 7th Station Hospital especially Major Richard E. Ross, M.C., A.U.S., Capt. Jerome J. Hoffman, M.C., A.U.S., of the Surgical Division, and Capt. James A. Vaughan, M.C., A.U.S., anaesthetist.

\section{REFERENCE}

Ladd, W. E., and Gross, R. E. (1940). New Engl. J. Med., 223, 917. 